\title{
Table of Contents and
}

\section{Guide to Abstract Numbers}

A Message from the Journal of Vestibular Research 79

Table of Contents and Guide to Abstract Numbers $\quad 81$

Introduction to the XXVI Bárány Society Meeting 83

$\begin{array}{lr}\text { General Information } & 87\end{array}$

$\begin{array}{ll}\text { Social Program } & 89\end{array}$

$2^{\text {nd }}$ Bárány Society Teaching Day $\quad 91$

$\begin{array}{ll}\text { Vestibular Rehabilitation Day } & 93\end{array}$

$\begin{array}{ll}\text { Program Overview } & 95\end{array}$

$\begin{array}{lr}\text { Program } & 99\end{array}$

$\begin{array}{lr}\text { Abstracts: Oral Sessions } & 149\end{array}$

$\begin{array}{lr}\text { Abstracts: Poster Sessions } & 269\end{array}$

$\begin{array}{lr}\text { Author Index } & 341\end{array}$

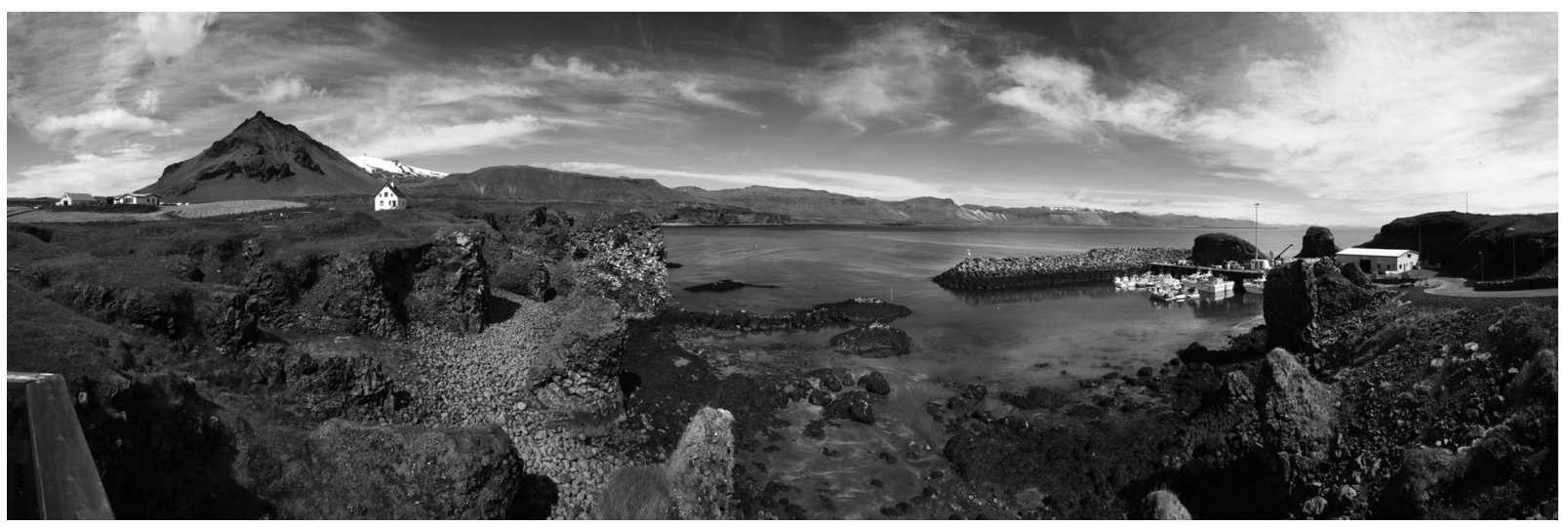




\section{Guide to Abstract Numbers}

Abstracts for oral presentations are designated by the letter A, B, C, or D followed by a number with the designation corresponding to the program for oral presentations. Submitted abstracts have been peerreviewed and selected by the Scientific Committee. Abstracts for poster presentations are designated as "P" followed by a letter and then a number; these abstracts also have been peer-reviewed and selected by the Scientific Committee. 